\title{
Au-Ag assembled on silica nanoprobes for visual semiquantitative detection of prostate-specific antigen
}

Hyung-Mo Kim¹', Jaehi Kim¹, Jaehyun An', Sungje Bock', Xuan-Hung Pham¹', Kim-Hung Huynh', Yoonsik Choi², Eunil Hahm ${ }^{1}$, Hobeom Song ${ }^{3}$, Jung-Won Kim³ ${ }^{3}$ Won-Yeop Rho ${ }^{4}$, Dae Hong Jeong ${ }^{2}$, Ho-Young Lee ${ }^{5}$,

Sangchul Lee ${ }^{6^{*}}$ and Bong-Hyun Jun ${ }^{1^{*}}$ (D)

\begin{abstract}
Background: Blood prostate-specific antigen (PSA) levels are widely used as diagnostic biomarkers for prostate cancer. Lateral-flow immunoassay (LFIA)-based PSA detection can overcome the limitations associated with other methods. LFIAbased PSA detection in clinical samples enables prognosis and early diagnosis owing to the use of high-performance signal reporters.

Results: Here, a semiquantitative LFIA platform for PSA detection in blood was developed using Au-Ag nanoparticles (NPs) assembled on silica NPs (SiO2@Au-Ag NPs) that served as signal reporters. Synthesized SiO2@Au-Ag NPs exhibited a high absorbance at a wide wavelength range (400-800 nm), with a high scattering on nitrocellulose membrane test strips. In LFIA, the color intensity of the test line on the test strip differed depending on the PSA concentration $(0.30-10.00 \mathrm{ng} / \mathrm{mL})$, and bands for the test line on the test strip could be used as a standard. When clinical samples were assessed using this LFIA, a visual test line with particular color intensity observed on the test strip enabled the early diagnosis and prognosis of patients with prostate cancer based on PSA detection. In addition, the relative standard deviation of reproducibility was $1.41 \%$, indicating high reproducibility, and the signal reporter showed good stability for 10 days.
\end{abstract}

Conclusion: These characteristics of the signal reporter demonstrated the reliability of the LFIA platform for PSA detection, suggesting potential applications in clinical sample analysis.

Keywords: Prostate-specific antigen, Lateral-flow immunoassay, Nanoparticle, Prostate cancer, Colorimetric assay, Colloid gold nanoparticle

\section{Background}

Prostate cancer $(\mathrm{PCa})$ is the second most common cancer in men worldwide and the fifth leading cause of cancer-related death [1]. PCa can be cured by radical

\footnotetext{
*Correspondence: slee@snubh.org; bjun@konkuk.ac.kr

${ }^{1}$ Department of Bioscience and Biotechnology, Konkuk University, Seoul, Korea

${ }^{6}$ Department of Urology, Seoul National University Bundang Hospital, Seongnam, Korea

Full list of author information is available at the end of the article
}

prostatectomy or radiation treatment (RT) during early stages; thus, early diagnosis is very important [2]. As the levels of prostate-specific antigen (PSA) increase after the onset of PCa, PSA is one of the most commonly used biomarkers for the diagnosis of $\mathrm{PCa}$ at the early stages, thereby reducing the mortality rates [3]. Based on the PSA levels, the following diagnoses are made: PSA $\leq 2.50 \mathrm{ng} /$ $\mathrm{mL}$, normal; PSA of $4.00-10.00 \mathrm{ng} / \mathrm{mL}$, early stage PCa; $\mathrm{PSA} \geq 10 \mathrm{ng} / \mathrm{mL}$, advanced stage [4]. In patients with $2.50-4.00 \mathrm{ng} / \mathrm{mL}$ PSA, the status of PCa is not clear, and studies have emphasized that re-adjustment of the cutoff 
value for PSA levels may be necessary [5-8]. Additionally, after radical prostatectomy-the standard treatment for localized $\mathrm{PCa}-$ measurement of serum PSA levels is important for monitoring PCa recurrence [9]. In particular, in previous studies, a cutoff value of $0.30 \mathrm{ng} / \mathrm{mL}$ PSA after curative treatment was suggested for predicting biochemical recurrence (BCR) after RT [10]. Accordingly, PSA levels after radical prostatectomy should be continuously examined because the measurement of PSA levels after surgery is a relatively simple approach for diagnosing BCR [11, 12]. However, healthy men who undergo PCa screening and patients with PCa who receive treatment and need close follow-up based on their PSA levels are forced to undergo many expensive tests, resulting in a high burden [13-15]. Therefore, the development of an inexpensive, simple method for PSA measurement that is suitable for various applications, including assessment of prognosis, is essential.

Enzyme-linked immunosorbent assay (ELISA)-one of the most commonly used methods to detect PSA-is often used for the identification of biomarkers owing to its specificity, reproducibility, quantitative nature, and low detection limit (pg/mL to $\mathrm{fg} / \mathrm{mL}$ level) [16]. However, PSA analysis using ELISA is time- and cost-intensive and requires well-trained technicians [17]. Lateral-flow immunoassay (LFIA) - which is based on test strips-has been widely recognized as an alternative to ELISA, owing to its economical and rapid analysis of biomolecules, such as PSA. LFIA is a low-cost, simple approach that can be employed on a large scale for clinical applications [18]. Moreover, LFIA enables visualized qualitative or semiquantitative analysis within $30 \mathrm{~min}$ [17]. For sensitive detection, optical nanoparticles, such as colloid gold nanoparticles (AuNPs) or silver nanoparticles (AgNPs), which are easy to prepare and exhibit strong optical reactions and affinity for antibodies during conjugation are widely used in LFIA [19-21]. In particular, AuNPs are most often employed with LFIA for qualitative and semiquantitative analyses [22]. These AuNPs have several advantages, including a high extinction cross-section, colloidal stability, and affinity for antibodies in the visible spectrum as evidenced using surface plasmon resonance [23]. In LFIA, signal reporters, such as AuNPs conjugated to the detection antibody, are captured on the test line of the LFIA nitrocellulose (NC) membrane together with the target, thereby enabling visualization of the result. When colloid AuNPs were used as signal reporters for detecting PSA in LFIA, PSA detection was confirmed visually up to $0.50-3.00 \mathrm{ng} / \mathrm{mL}$ [24-27]. Although biosensing is the primary use of AuNPs, many methods based on core/shell-type NPs, including conventional AuNPs for enabling the detection of PSA signals with high sensitivity in LFIA have been reported. Xia et al. designed a colorimetric LFIA platform using core/shell-type Au@ Pt NPs as signal reporters in low-sensitivity mode and color-catalyzed Au@Pt NPs as signal reporters using a color molecule in the high-sensitivity mode for the detection of PSA [25]. Under optimized conditions, the naked eye detection limits of low- and high-sensitivity modes were $2 \mathrm{ng} / \mathrm{mL}$ and $20 \mathrm{pg} / \mathrm{mL}$, respectively. However, detection of various concentrations of PSA using this LFIA platform is a complicated procedure owing to the separation of the low- and high-sensitivity modes. López et al. developed silver and gold enhancement methods for LFIA, which enabled simple detection of PSA by the naked eye [24]. Under optimized conditions, the nakedeye detection limit was $0.1 \mathrm{ng} / \mathrm{mL}$ when silver-enhanced AuNPs were used; this was five times lower than that for existing AuNPs. However, this method exhibits nonspecific binding in LFIA, and as it is difficult to handle samples via centrifugation, obtaining $100 \%$ recovery following antibody introduction is challenging.

In LFIA, the conditions used for the signal reporter should be efficient and reproducible, and there should be no nonspecific binding [28]. Signal reporters based on metal NPs assembled on silica NPs could overcome the problems of efficiency, reproducibility, and binding specificity owing to the ease of handling and surface modulation. The sizes of silica NPs can also be easily modulated, and modification of the surface is possible, thereby enabling the metal NPs to be introduced on the surface of silica NP [29]. Moreover, metal NP assembly on silica NPs could result in strong localized surface plasmon resonance (LSPR) compared with single NPs [29]. Among metal NPs, Au-Ag alloy NPs exhibit stronger LSPR than single AuNPs or AgNPs and show various colors when the AuNP to AgNP ratio is altered [30,31]. Based on these advantages of $\mathrm{Au}-\mathrm{Ag}$ alloy NPs, our group recently reported nanostructures with $\mathrm{Au}-\mathrm{Ag}$ NPs clustered on a silica core [31-33]. These nanostructures had a single broad absorbance peak, and the formation of optimized $\mathrm{Au}-\mathrm{Ag}$ alloy NPs showed distinct colors depending on the target concentration [34, 35].Accordingly, in this study, we developed an LFIA platform using $\mathrm{Au}-\mathrm{Ag}$ alloy NPs assembled on silica NPs $\left(\mathrm{SiO}_{2} @ \mathrm{Au}-\mathrm{Ag} \mathrm{NPs}\right)$ for the visual analysis of PSA. $\mathrm{SiO}_{2} @ \mathrm{Au}-\mathrm{Ag}$ NPs were synthesized using an optimized synthesis method. Various concentrations of PSA were detected based on the color intensity of the test line in the test strip. By using this result as a standard, it was possible to semi-quantitatively detect PSA concentrations corresponding to those associated with early diagnosis and prognosis in the clinical samples. In addition, this LFIA platform with $\mathrm{SiO}_{2} @ \mathrm{Au}-\mathrm{Ag}$ NPs was stable exhibited high reproducibility in terms of results for 10 days with signal intensity. 


\section{Materials and methods Materials}

Tetraethyl orthosilicate (TEOS), 3-aminopropyltriethoxysilane (APTS), silver nitrate $\left(\mathrm{AgNO}_{3}\right)$, chloroauric acid $\left(\mathrm{HAuCl}_{4}\right)$, ascorbic acid (AA), polyvinylpyrrolidone (wt. 10,000 , PVP), sodium borohydride $\left(\mathrm{NaBH}_{4}\right)$, succinic anhydride, 11-mercaptoundecanoic acid (MUA), N-(3dimethylaminopropyl)- $N^{\prime}$-ethylcarbodiimide (EDC) hydrochloride, $\mathrm{N}$-hydroxysulfosuccinimide (Sulfo-NHS) sodium salt, 2-(N-Morpholino)ethanesulfonic acid hydrate (MES hydrate), phosphate-buffered saline (PBS, $\mathrm{pH}$ 7.4), Tween 20, and ethanolamine were purchased from Sigma-Aldrich (St. Louis, MO, USA). Aqueous ammonium hydroxide $\left(\mathrm{NH}_{4} \mathrm{OH}, 27 \%\right)$ and 1-methyl2-pyrrolidinone (NMP) were purchased from Daejung (Siheung, Korea). The backing card, nitrocellulose (NC) membrane, absorbent pad, cassette, monoclonal antiPSA antibody (mouse, anti-PSA Ab; cat. nos. 14801 and 14,803), and goat anti-rabbit IgG Ab were purchased from Bore Da Biotech Co. Ltd. (Seongnam, Korea).

\section{Synthesis of $\mathrm{SiO}_{2} @ \mathrm{Au}-\mathrm{Ag} \mathrm{NPs}$}

The $\mathrm{SiO}_{2} @ \mathrm{Au}-\mathrm{Ag}$ NPs were synthesized as previously reported [36]. First, the $\mathrm{SiO}_{2} \mathrm{NPs}$ (approximately $160 \mathrm{~nm}$ in diameter) were synthesized using the Stöber method [37]. The mixture containing of TEOS (1.6 mL) and $\mathrm{NH}_{4} \mathrm{OH}(3 \mathrm{~mL})$ in ethanol $(40 \mathrm{~mL})$ was stirred for $20 \mathrm{~h}$ at $25{ }^{\circ} \mathrm{C}$. The mixture was centrifuged at $8500 \mathrm{rpm}$ for $15 \mathrm{~min}$, and particles were washed several times using $\mathrm{EtOH}$. For introducing the amine group onto the surface of silica NPs, the mixture containing $\mathrm{SiO}_{2}$ NPs $(200 \mathrm{mg})$, absolute EtOH $(4 \mathrm{~mL})$, APTS $(200 \mu \mathrm{L})$, and $\mathrm{NH}_{4} \mathrm{OH}(40 \mu \mathrm{L})$ was mixed and stirred for $12 \mathrm{~h}$ at $25^{\circ} \mathrm{C}$. Next, the mixture was centrifuged at $8500 \mathrm{rpm}$ for $15 \mathrm{~min}$ and washed several times using EtOH. For preferentially introducing AuNPs (7 nm) onto the surface of aminated $\mathrm{SiO}_{2} \mathrm{NPs}\left(\mathrm{SiO}_{2} @ \mathrm{Au} \mathrm{NPs}\right)$, AuNPs were synthesized using $\mathrm{HAuCl}_{4}$ and $\mathrm{NaBH}_{4}$ for $12 \mathrm{~h}$ with gentle shaking at $25^{\circ} \mathrm{C}$. Consequently, AuNPs $(7 \mathrm{~nm}$ in diameter), which had negatively charged ligands on their surfaces, were obtained after washing with centrifugation. Subsequently, aminated $\mathrm{SiO}_{2} \mathrm{NPs}(1 \mathrm{mg})$ resuspended in $\mathrm{EtOH}$ were mixed with AuNPs (1 mM) in deionized water, and the mixture was sonicated for $30 \mathrm{~min}$ and incubated overnight. The mixture was centrifuged at $8500 \mathrm{rpm}$ for $15 \mathrm{~min}$ and washed several times using EtOH. Thereafter, to create an Ag shell on the surface of $\mathrm{SiO}_{2} \mathrm{NPs}$, the NPs $(200 \mu \mathrm{g})$ were dispersed in $9.8 \mathrm{~mL}$ water containing $20 \mu \mathrm{L}$ of $10 \mathrm{mM}$ ascorbic acid and $10 \mathrm{mg}$ polyvinylpyrrolidone. This mixture was then stirred after the addition of $10 \mathrm{mM} \mathrm{AgNO}_{3}(20 \mu \mathrm{L})$ for $15 \mathrm{~min}$ at $25^{\circ} \mathrm{C}$ to reduce $\mathrm{Ag}^{+}$ ions to $\mathrm{Ag}$. Next, the reduction steps were repeated with $300 \mu \mathrm{M} \mathrm{AgNO}_{3}(20 \mu \mathrm{L})$. The mixture was centrifuged at
$8500 \mathrm{rpm}$ for $15 \mathrm{~min}$, washed several times using $\mathrm{EtOH}$, and dispersed in $\mathrm{EtOH}$.

\section{Conjugation of anti-PSA Ab onto the surface of $\mathrm{SiO}_{2} @ \mathrm{Au}-$ Ag NPs}

For introducing the carboxyl groups onto the surface, $\mathrm{SiO}_{2} @ \mathrm{Au}-\mathrm{Ag}$ NPs reconstituted in EtOH $(200 \mu \mathrm{g} / \mathrm{mL}$, $1 \mathrm{~mL}$ ) were mixed with $2 \mathrm{mM}$ mercaptoundecanoic acid prepared in $\mathrm{EtOH}$ for $16 \mathrm{~h}$ at $25{ }^{\circ} \mathrm{C}$. The mixture was washed several times with deionized water via centrifugation at 13,000 rpm for $10 \mathrm{~min}$, followed by redispersion in $50 \mathrm{mM}$ MES buffer ( $\mathrm{pH}$ 5.0). To activate the groups on the surface of carboxylated $\mathrm{SiO}_{2} @ \mathrm{Au}-\mathrm{Ag}$ NPs, EDC hydrochloride $(2 \mathrm{mg})$ and sulfo-NHS $(2 \mathrm{mg})$ were added to carboxylated $\mathrm{SiO}_{2} @ \mathrm{Au}-\mathrm{Ag}$ NPs prepared in $50 \mathrm{mM}$ MES buffer, and the mixture was stirred for $30 \mathrm{~min}$ at $25{ }^{\circ} \mathrm{C}$. After removing the supernatant via centrifugation, NPs were dispersed in MES buffer. $\mathrm{SiO}_{2} @ \mathrm{Au}-\mathrm{Ag}$ NPs were added to the anti-PSA Ab mixture (cat. no. 14803; $1 \mathrm{mg} / \mathrm{mL}, 150 \mu \mathrm{L}$ ), and the mixture was stirred for $2 \mathrm{~h}$ at $25{ }^{\circ} \mathrm{C}$. After centrifugation, anti-PSA Ab-introduced $\mathrm{SiO}_{2} @ \mathrm{Au}-\mathrm{Ag}$ NPs in $50 \mathrm{mM}$ MES were mixed with ethanolamine $(3.2 \mu \mathrm{L})$, and the mixture was stirred for $30 \mathrm{~min}$ at $25{ }^{\circ} \mathrm{C}$. The mixture was then washed several times with $0.5 \%$ bovine serum albumin (BSA) prepared in phosphate-buffered saline (PBS) via centrifugation at $13,000 \mathrm{rpm}$ for $10 \mathrm{~min}$ and then redispersed in $0.5 \% \mathrm{BSA}$ in PBS.

\section{Synthesis of anti-PSA Ab-conjugated colloid AuNPs}

AuNPs (15 nm diameter) were prepared as reported previously [38]. Water $(99 \mathrm{~mL})$ and $25 \mathrm{mM} \mathrm{HAuCl} \cdot 3 \mathrm{H}_{2} \mathrm{O}$ $(1 \mathrm{~mL})$ were mixed in an Erlenmeyer flask and stirred vigorously for $5 \mathrm{~min}$ at $100{ }^{\circ} \mathrm{C}$. Subsequently, 3.3\% sodium tricitrate in deionized water was added rapidly to the mixture, and the mixture was stirred for an additional $1 \mathrm{~h}$. Thereafter, the mixture was cooled to room temperature, and its volume was adjusted to $100 \mathrm{~mL}$ with deionized water. Subsequently, the $\mathrm{pH}$ of the mixture was adjusted to 8.5 using polyvinylpyrrolidone $(100 \mathrm{mg})$.

Thereafter, $2 \mathrm{mM}$ AuNPs $(1 \mathrm{~mL})$ in deionized water was mixed with anti-PSA Ab (cat. no. 14803; $1 \mathrm{mg} / \mathrm{mL}$, $200 \mu \mathrm{L}$ ), and the mixture was incubated overnight at $4{ }^{\circ} \mathrm{C}$. After completion of the reaction, the mixture was centrifuged at 17,000 rpm for $15 \mathrm{~min}$ for sedimentation and dispersed in PBS containing 0.5\% BSA.

\section{Characterization of $\mathrm{SiO}_{2} @ \mathrm{Ag} @ \mathrm{SiO}_{2} \mathrm{NPs}$}

Transmission electron microscopy (TEM) was performed using a LIBRA 120 (Carl Zeiss, Oberkochen, Germany). Field emission-scanning electron microscopy (FE-SEM) was performed using an SU-8010 instrument (Hitachi, Tokyo, Japan). UV-Vis extinction spectra were obtained 
with an OPTIZEN POP instrument (Mecasys, Daejeon, Korea).

\section{Preparation of test strips}

The test strips comprised a backing card, NC membrane, and absorbent pad (Additional file 1: Fig. S1). After assembling the $\mathrm{NC}$ membrane and absorbent pad on the backing card, anti-PSA Ab prepared in PBS (cat. no. $14801 ; 1 \mathrm{mg} / \mathrm{mL}$ ) was sprayed on the test line, and the control line was sprayed with goat anti-rabbit IgG prepared in PBS $(1 \mathrm{mg} / \mathrm{mL})$ using a dispenser. The strip was dried for approximately $24 \mathrm{~h}$. Next, $0.1 \%$ BSA was applied and the assembly was dried for at least 1 day. Finally, the absorbent pad was assembled on the backing card. After cutting the strips to a width of $4 \mathrm{~mm}$, the test strips were prepared.

\section{Collection of clinical samples}

Before starting this study, all clinical samples were obtained with written informed consent, and the study design was approved by the Seoul National University Bundang Hospital (IRB No. B 1711/432-302).
Analysis of colored test lines in the test strips

To measure the color intensity of the test line on the test strips, images of test strips were captured as 8-byte images using an ImageQuant LAS-4000 (GE Healthcare, Chicago, IL, USA). ${ }^{31}$ Captured images were analyzed using ImageJ ver. 1.53a (National Institutes of Health, Bethesda, MD, USA).

Stability test for $\mathrm{SiO}_{2} @ \mathrm{Au}-\mathrm{Ag}$ NPs as signal reporters in LFIAnti-PSA Ab-conjugated $\mathrm{SiO}_{2} @ \mathrm{Au}-\mathrm{Ag}$ NPs were stored in $0.5 \%$ BSA in PBS to evaluate stability for 14 days. Every 2 days, stored anti-PSA Ab-conjugated $\mathrm{SiO}_{2} @ \mathrm{Au}-\mathrm{Ag}$ NPs were mixed with clinical samples spiked with $0.54 \mathrm{ng} / \mathrm{mL}$ PSA, and LFIA was performed in three batches. After analysis, the test strip was checked visually, and the color intensity of the test line of the test strip was measured using ImageJ.

\section{Results and Discussion}

\section{Synthesis of $\mathrm{SiO}_{2} @ A u-A g$ NPs}

The process used for synthesizing $\mathrm{Au}-\mathrm{Ag}$ alloy NPs assembled on silica NPs $\left(\mathrm{SiO}_{2} @ \mathrm{Au}-\mathrm{Ag} \mathrm{NPs}\right)$ is described in Fig. 1a. $\mathrm{SiO}_{2} \mathrm{NPs}(160 \mathrm{~nm})$ were synthesized using the Stöber method (Fig. 1b(i)) [29]. Subsequently, the

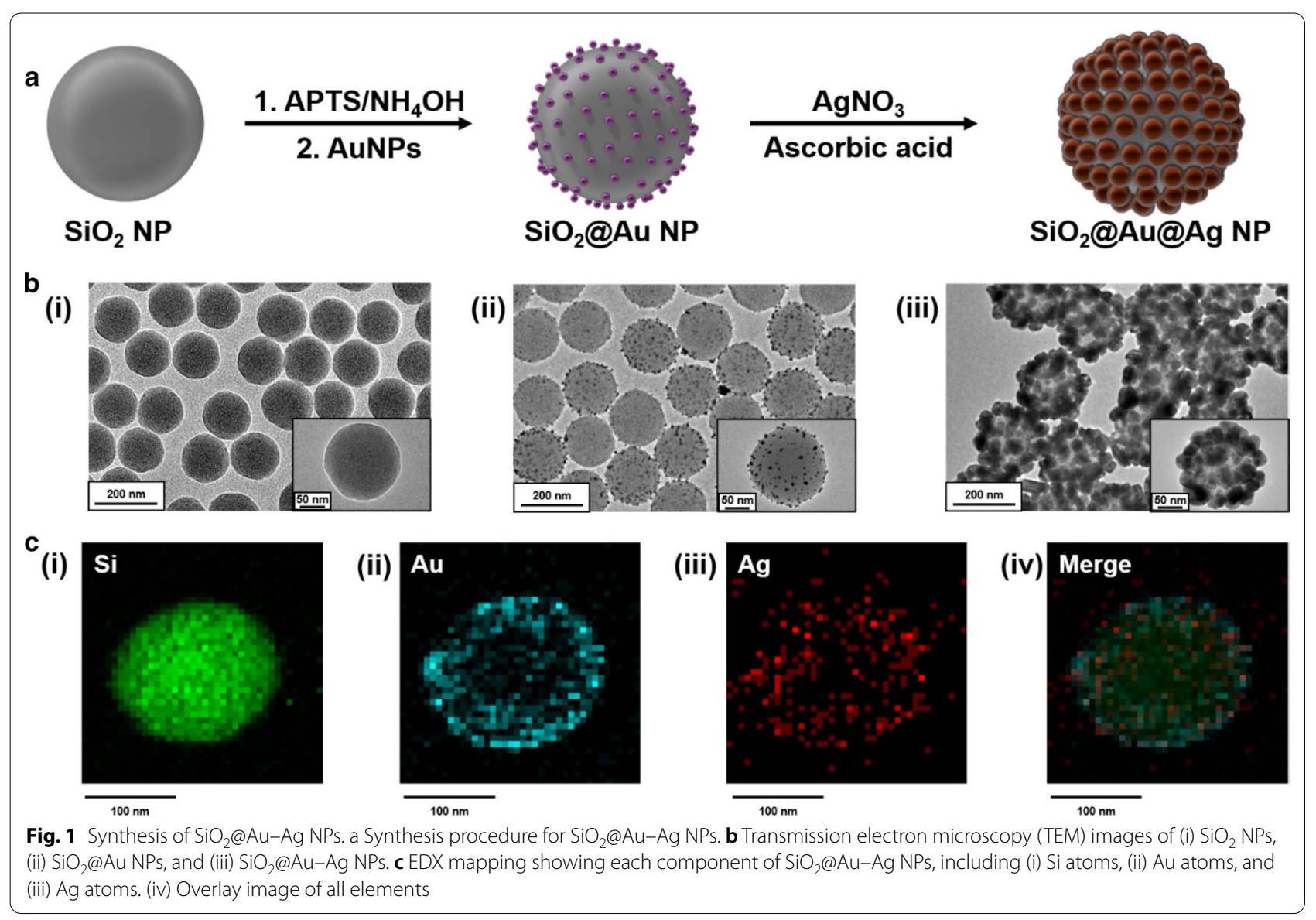


NP surfaces were modified to amine groups, and colloid AuNPs $(7 \mathrm{~nm})$ were introduced onto the $\mathrm{SiO}_{2} \mathrm{NPs}\left(\mathrm{SiO}_{2} @\right.$ $\mathrm{Au}$ NPs, Fig. 1b(ii)). Silver ions on the surface of AuNPs were reduced, yielding $\mathrm{SiO}_{2} @ \mathrm{Au}-\mathrm{Ag} \mathrm{NPs}$ (Fig. 1b(iii)) [32]. The chemical compositions of the $\mathrm{SiO}_{2} @ \mathrm{Au}-\mathrm{Ag}$ NP were investigated using energy dispersive spectroscopy (EDX) mapping. The locations of the $\mathrm{Si}, \mathrm{Au}$, and $\mathrm{Ag}$ atoms in the $\mathrm{SiO}_{2} @ \mathrm{Au}-\mathrm{Ag}$ NPs are shown in Fig. 1c(iiv). EDX revealed that both AuNPs and AgNPs were located on the surface of silica NPs. These results demonstrated the successful fabrication of $\mathrm{SiO}_{2} @ \mathrm{Au}-\mathrm{Ag}$ NPs. Next, we investigated the characteristics of the synthesized $\mathrm{SiO}_{2} @ \mathrm{Au}-\mathrm{Ag}$ NPs. Figure 2a(i) shows the UV-vis absorption spectra for each sample during the synthesis of $\mathrm{SiO}_{2} @ \mathrm{Au}-\mathrm{Ag} \mathrm{NPs} . \mathrm{SiO}_{2} @ \mathrm{Au} \mathrm{NPs}$ showed unique absorbance peaks at approximately $520 \mathrm{~nm}$ (compared with $\mathrm{SiO}_{2} \mathrm{NPs}$ ), and $\mathrm{SiO}_{2} @ \mathrm{Au}-\mathrm{Ag}$ NPs showed a wide absorbance band (400-800 nm; compared with $\mathrm{SiO}_{2} @ \mathrm{Au}$ NPs) [36]. These results demonstrated that an Ag layer was formed on the surface of AuNPs immobilized on $\mathrm{SiO}_{2} \mathrm{NPs}$. Figure 2a(ii) shows color images of $\mathrm{SiO}_{2} \mathrm{NPs}$, $\mathrm{SiO}_{2} @ \mathrm{Au} \mathrm{NPs}$, and $\mathrm{SiO}_{2} @ \mathrm{Au}-\mathrm{Ag} \mathrm{NPs}\left(1 \times 10^{10}\right.$ particles/ $\mathrm{mL}$ ) dispersed in EtOH. Assembly of NPs is known to induce plasmon vibrations, which cause a color change [39]. Visually, because the band of the finally synthesized $\mathrm{SiO}_{2} @ \mathrm{Au}-\mathrm{Ag} \mathrm{NPs}$ exhibited a wide spectrum of absorbance, it appeared dark brown in EtOH.

We also investigated the scattering effect of $\mathrm{SiO}_{2} @$ $\mathrm{Au}-\mathrm{Ag} \mathrm{NPs}$ on light in the NC membranes of test strips. Normally, the band on the NC membrane absorbs and scatters light according to the plasmon properties of the signal reporter. As previously reported, a series of two consecutive 1/4 dilutions of $\mathrm{SiO}_{2} @ \mathrm{Au}-\mathrm{Ag} \mathrm{NPs}, \mathrm{SiO}_{2} @$ Au NPs, and colloid AuNPs (size: $15 \mathrm{~nm}, \lambda_{\text {abs, max }}: 520 \mathrm{~nm}$ ) were prepared (Additional file 1: Fig. S3). The prepared samples were dropped by spotting on the circular NC membrane $(6 \mathrm{~mm})$, and visibility was confirmed based on the distribution of color spots according to NP dilution.

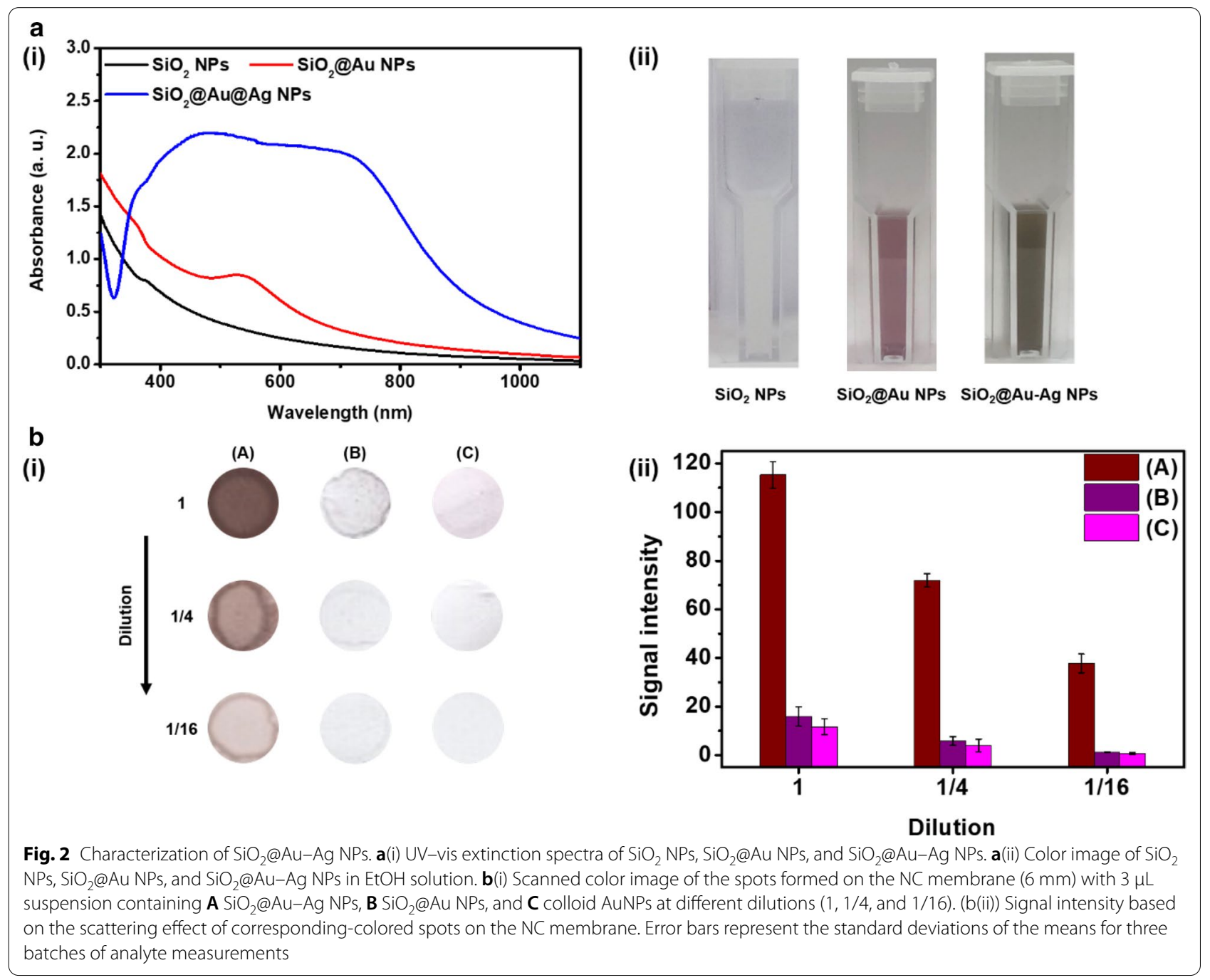


First, $3 \mu \mathrm{L}$ of each sample was dropped onto the NC membrane and dried, and then the NC membrane was scanned. Figure $2 \mathrm{~b}(\mathrm{i})$ shows an image of colored spots obtained upon applying a dilution (top to bottom). Upon visual analysis, the colored spots faded as the concentration of each sample decreased; when all signal reporters were diluted to $1 / 16$, only the color intensity of $\mathrm{SiO}_{2} @$ $\mathrm{Au}-\mathrm{Ag}$ NPs was observed. When comparing the color intensity between all signal reporters, $\mathrm{SiO}_{2} @ \mathrm{Au}-\mathrm{Ag}$ NPs showed the brightest signal compared with other samples at all dilutions (Fig. 2b(ii)). These results confirmed that $\mathrm{SiO}_{2} @ \mathrm{Au}-\mathrm{Ag}$ NPs were suitable for use in the LFIA platform owing to their high scattering effect in the NC membrane of the test strips.

\section{Changes in the color intensity of the test line according to the concentration of PSA in LFIA}

To utilize $\mathrm{SiO}_{2} @ \mathrm{Au}-\mathrm{Ag}$ NPs in the LFIA platform, the surface of $\mathrm{SiO}_{2} @ \mathrm{Au}-\mathrm{Ag}$ NPs was modified at carboxyl groups using 11-mercaptoundecanoic acid. Next, the surface was activated using EDC/sulfo-NHS, and antiPSA Abs were conjugated onto the surface. The UV-Vis absorption spectrum of anti-PSA Ab-conjugated $\mathrm{SiO}_{2} @$ $\mathrm{Au}-\mathrm{Ag}$ NPs was preserved after conjugation of anti-PSA Abs (Additional file 1: Fig. S2). The working principle of the LFIA is shown in Fig. 3a. The test strip comprised an absorbent pad and an NC membrane; after assembling the components, the dipstick method was used for PSA and anti-PSA Ab-conjugated $\mathrm{SiO}_{2} @ \mathrm{Au}-\mathrm{Ag}$ NPs in 96-well plates. The results showed that PSA and antiPSA Ab-conjugated $\mathrm{SiO}_{2} @ \mathrm{Au}$-Ag NPs formed complexes in the wells, and test strips were then dipped in the corresponding wells. After $15 \mathrm{~min}$, the test line on the test strip turned dark brown, a phenomenon that could be confirmed visually owing to the interaction between the complex and the capture antibody.

Fig. $3 \mathrm{~b}$ and c show the results of concentration-specific analysis of PSA using the newly developed LFIA platform. Analysis was performed at PSA concentrations ranging from 0 to $300.00 \mathrm{ng} / \mathrm{mL}$. As the concentration of PSA increased, more immune complexes were formed at the test line, and the brown color of the test line became darker, as expected. At a concentration of $0.30 \mathrm{ng} / \mathrm{mL}$, the test line could be observed with the naked eye (Fig. 3b). Additional file 1: Fig. S4 shows scanning electron microscopy (SEM) images of the test line on test strips (at PSA $=0 \mathrm{ng} / \mathrm{mL}$ and PSA = $300.00 \mathrm{ng} / \mathrm{mL}$ ). $\mathrm{SiO}_{2} @ \mathrm{Au}-\mathrm{Ag} \mathrm{NPs}$ bound to the NC membrane through PSA were clearly different from the test line for $0 \mathrm{ng} / \mathrm{mL}$ in SEM. When more PSA antigen-SiO $\mathrm{S}_{2} \mathrm{Au}-\mathrm{Ag}$ NPs complexes were captured on the test line, the signal intensity of the test line increased as the concentration of PSA increased (Fig. 3c). Analysis of the calibration curves based on the signal intensity revealed that the limit of detection (LOD)

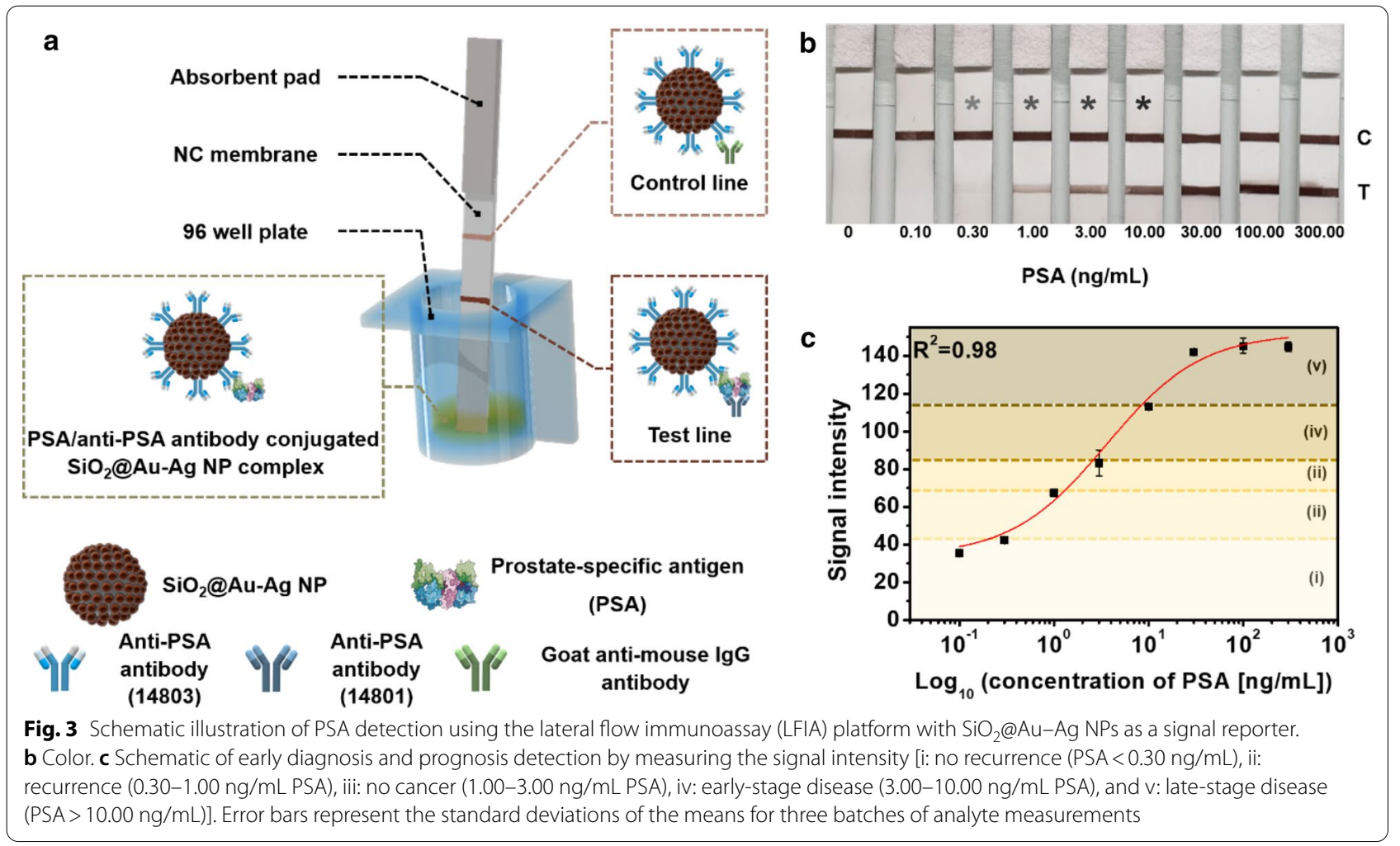


was $0.20 \mathrm{ng} / \mathrm{mL}$. Based on these semiquantitative results and PSA concentrations of 1.00-10.00 and 0.30-1.00 ng/ $\mathrm{mL}$, the color intensity of the test line on the test strip was used as a standard for early diagnosis. Specifically, normal status was indicated as a signal in the 1.00-3.00 $\mathrm{ng} / \mathrm{mL}$ PSA section of the test strip; early-stage disease was indicated as a signal in the $3.00-10.00 \mathrm{ng} / \mathrm{mL}$ PSA section of the test strip; and late-stage disease was indicated as a signal at greater than $10.00 \mathrm{ng} / \mathrm{mL}$ PSA. In addition, to monitor for recurrence, biochemical recurrence was indicated as a signal in the $0.30-1.00 \mathrm{ng} / \mathrm{mL}$ PSA section, whereas no recurrence was indicated as a signal at less than $0.30 \mathrm{ng} / \mathrm{mL}$ PSA. As a standard, a band showing different colors dependent on the concentration at the test line was sufficient to distinguish each stage, and the low sensitivity was suitable for use in patient prognosis. For comparison of the detection ability of the $\mathrm{SiO}_{2} @ \mathrm{Au}-\mathrm{Ag} \mathrm{NPs}$, existing colloid AuNPs conjugated to anti-PSA Ab were evaluated, and the LODs of these two signal reporters were calculated at the same concentration of PSA (Additional file 1: Fig. S5). The band on the test line could be observed at a PSA concentration of $1.00 \mathrm{ng} / \mathrm{mL}$ when colloid AuNPs were used as the signal reporter. Moreover, the color intensity difference according to the PSA concentration for each strip using colloid AuNPs was not greater than that of $\mathrm{SiO}_{2} @ \mathrm{Au}-\mathrm{Ag}$ NPs. The LOD determined from the standard deviation was $0.82 \mathrm{ng} / \mathrm{mL}$ for colloid AuNPs. Based on the calculated LODs, $\mathrm{SiO}_{2} @ \mathrm{Au}-\mathrm{Ag}$ NPs were approximately four times more sensitive than colloid AuNPs and $\mathrm{SiO}_{2} @ A u$ NPs, and these results demonstrated the high performance of the prepared $\mathrm{SiO}_{2} @ \mathrm{Au}-\mathrm{Ag}$ NPs for PSA detection with
LFIA. Additionally, these results demonstrated the applicability of this approach as a standard.

\section{Clinical validation of LFIA for PSA detection}

PSA detection in clinical samples is essential for assessing the performance and practical applicability of the LFIA platform. Therefore, we evaluated the applicability of LFIA with the standard obtained from the previous results using $\mathrm{SiO}_{2} @ \mathrm{Au}-\mathrm{Ag}$ NPs for PSA detection in clinical samples. Previously, clinical samples $(1:<0.01$ $\mathrm{ng} / \mathrm{mL}, 2: 0.80 \mathrm{ng} / \mathrm{mL}, 3: 2.01 \mathrm{ng} / \mathrm{mL}$, $4: 5.61 \mathrm{ng} / \mathrm{mL}$, and 5: $12.84 \mathrm{ng} / \mathrm{mL}$ ) were prepared by selecting samples corresponding to different sections of the standard obtained from the above results. When applying actual clinical samples to the LFIA platform, the amount of clinical sample used was $30 \mu \mathrm{L}$, which is less than that used for conventional enzyme-linked immunosorbent assays [40]. Clinical samples with PSA concentrations corresponding to each section were used, and PSA samples with PSA concentrations of less than $0.01 \mathrm{ng} / \mathrm{mL}$ were used as negative controls. As shown in Fig. 4a, except for the negative control (strip 1), all other PSA-positive samples showed bands on the test line. When measuring the color intensity of the band on the test line for each strip, the color intensities were correlated with the concentration of PSA. Additionally, when visually comparing the results with the color intensity of the standard, we confirmed that the bands produced by the clinical samples were within the appropriate section of the test strip (Fig. 4b). Thus, PSA in clinical samples was visually different from that in negative control samples, even at low concentrations, when using the prepared assay system.

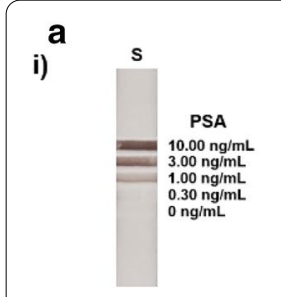

ii)

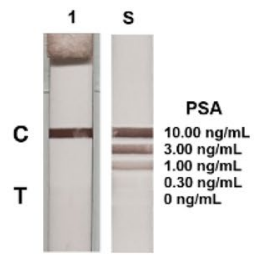

iii)

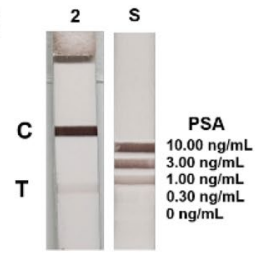

iv)

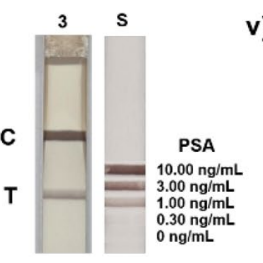

v)

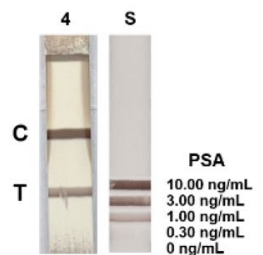

vi)

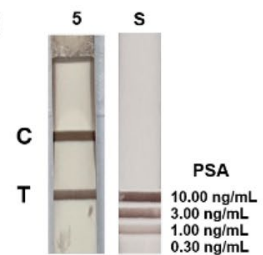

b

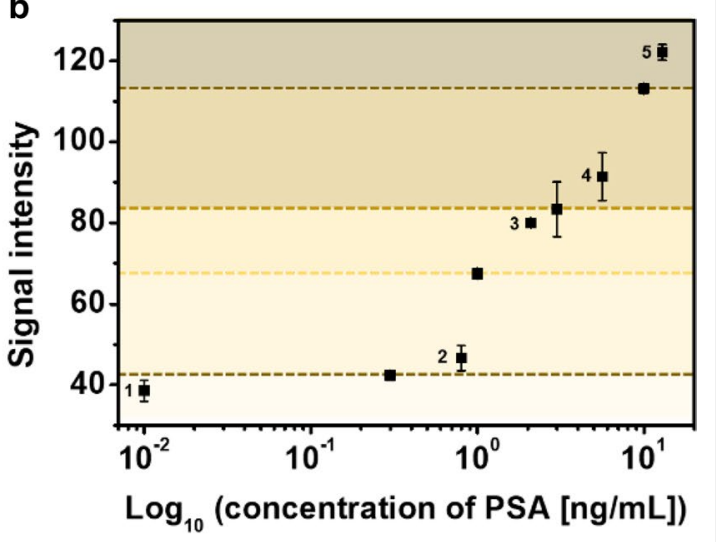

Fig. 4 Application of clinical samples with $\mathrm{SiO}_{2} @ \mathrm{Au}-\mathrm{Ag} N \mathrm{NP}$ as a signal reporter by comparison with the standard in LFIA. a Color image test line (T) on each test strip (i: PSA standard (S), ii PSA $0.01 \mathrm{ng} / \mathrm{mL}$ (1), iii: $0.80 \mathrm{ng} / \mathrm{mL}$ PSA (2), iv: $2.01 \mathrm{ng} / \mathrm{mL}$ PSA (3), v: $5.61 \mathrm{ng} / \mathrm{mL}$ PSA (4), and vi: $12.84 \mathrm{ng} / \mathrm{mL}$ PSA (5). b Measurement of signal intensity using clinical samples with the standard in the LFIA platform. Error bars represent standard deviations of the means for three batches of analyte measurements 
In the LFIA using $\mathrm{SiO}_{2} @ \mathrm{Au}-\mathrm{Ag}$ NPs, because the visual LOD of the test line was $0.30 \mathrm{ng} / \mathrm{mL}$ PSA, a clinical sample with a PSA concentration of $0.32 \mathrm{ng} / \mathrm{mL}$ was applied to the LFIA to confirm the visual LOD in clinical samples. Importantly, the intensity at the test line appeared similar to that in the standard but was slightly higher when the results were compared using ImageJ (Additional file 1: Fig. S6). Thus, these results showed that the visual LOD was consistent in clinical samples. In this study, complete quantitative analysis was difficult using the developed LFIA platform. However, the platform was suitable for screening because the stage of progression could be distinguished through analysis of the color intensity during early diagnosis and prognosis [41].

\section{Reproducibility and stability tests using $\mathrm{SiO}_{2} @ A u-A g ~ N P s$ in the LFIA platform}

To validate our clinical sample analysis, we assessed the reproducibility of LFIA for PSA detection in serum using $\mathrm{SiO}_{2} @ \mathrm{Au}-\mathrm{Ag}$ NPs and the storage stability of $\mathrm{SiO}_{2} @ \mathrm{Au}-\mathrm{Ag} \mathrm{NPs}$ as the signal reporter for LFIA application. First, the reproducibility test was performed with 10 batches of clinical samples (0.53 ng/mL PSA) simultaneously. As shown in Fig. 5a(i), the color intensity of the test line on the test strip was visually constant for samples with the same PSA concentration. The signal intensity of the test line on each test strip was analyzed using ImageJ (Fig. 5a(ii)), and the relative standard deviation (RSD) of the color intensity of the test line for the 10 batches was $1.41 \%$, indicating high reliability [42]. Therefore, these findings confirmed the reproducible performance of the developed platform for the detection of PSA. Second, storage stability tests were conducted using $\mathrm{SiO}_{2} @ \mathrm{Au}-\mathrm{Ag}$ NPs stored in 0.5\% BSA for the evaluation of clinical samples $(0.56 \mathrm{ng} / \mathrm{mL}$ PSA) with the developed LFIA platform. Visually, the color of the test line in the test strip was almost constant until approximately 10 days (Fig. 5b(i)). Similar results were observed upon analysis of the signal intensity of the test line using ImageJ (Fig. 5b(ii)). The RSD of the signal intensity was $0.96 \%$ for day 10 , indicating high reliability. Based on these results, we concluded that the developed platform had high reproducibility in terms of performance, even after storage for 10 days.

\section{a}

(i)

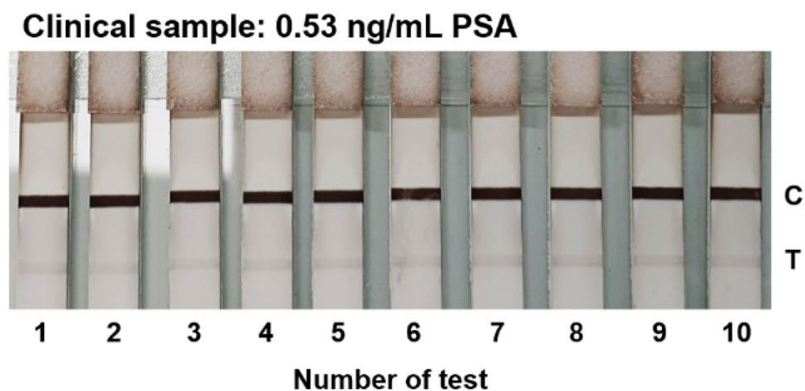

b

(i)

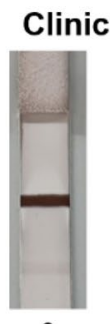

0

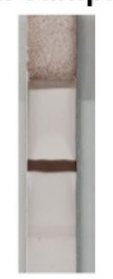

2

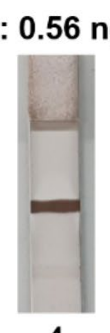

4

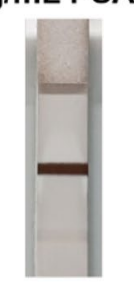

6

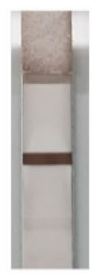

8

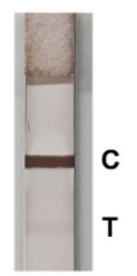

10 (ii)

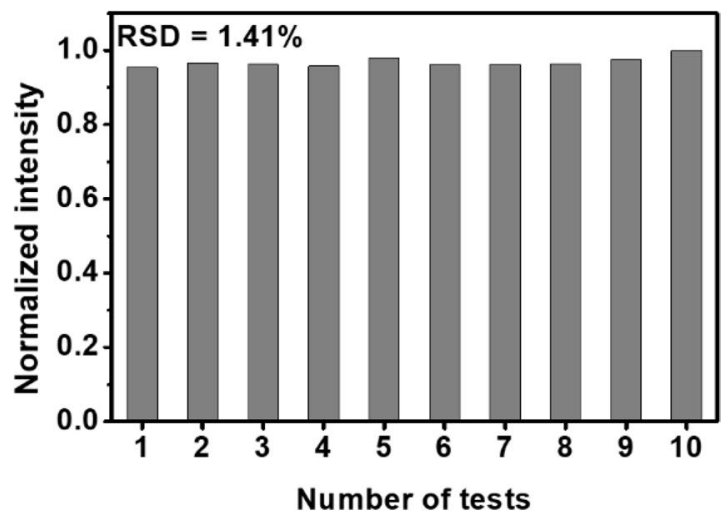

(ii)

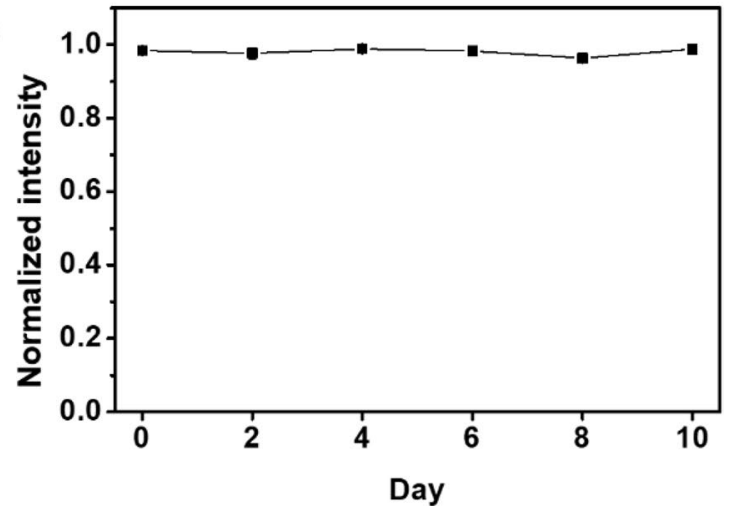

Fig. 5 a Test of reproducibility using $\mathrm{SiO}_{2} @ A u-A g ~ N P s$ as a signal reporter with clinical samples $(0.53 \mathrm{ng} / \mathrm{mL}$ PSA) in LFIA. (i) Color images and (ii) measurement of signal in-tensity. b Test of stability using $\mathrm{SiO}_{2} @ A u-A g ~ N P s$ with clinical sample $(0.56 \mathrm{ng} / \mathrm{mL}$ PSA) in LFIA. (i) Color image and (ii) measurement of signal intensity. Error bars represent standard deviations of the means for three batches of analyte measurements 


\section{Conclusion}

Herein, we described a visual LFIA with $\mathrm{SiO}_{2} @ \mathrm{Au}-\mathrm{Ag}$ NPs as detection signal reporters for semiquantitative detection of PSA in clinical samples. $\mathrm{SiO}_{2} @ \mathrm{Au}-\mathrm{Ag}$ NPs exhibited a broad absorption spectrum of 400-800 $\mathrm{nm}$ as $\mathrm{Au}-\mathrm{Ag}$ NPs were successfully assembled onto $\mathrm{SiO}_{2}$ NPs, and the scattering effect was significantly superior to that of $\mathrm{SiO}_{2} @ \mathrm{Au}$ NPs and colloid AuNPs. In addition, in the LFIA platform for PSA detection, we observed a color change that depended on the PSA concentration, and these results were used as a standard for semiquantitative analysis. Furthermore, PSA could be visually detected in clinical samples, and the color intensity corresponded to the PSA concentration, providing a platform for semiquantitative analysis and enabling diagnosis and prognosis. In addition, in reproducibility tests using clinical samples, the RSD for 10 batches was $1.41 \%$, indicating high reproducibility, and the results of stability tests using $\mathrm{SiO}_{2} @ \mathrm{Au}-\mathrm{Ag}$ NPs in 0.50\% BSA solution showed that the signal was almost constant after storage for 10 days. Overall, these results showed the possibility of application of this approach for early diagnosis and prognosis by comparison with the standard. The developed LFIA platform showed limited ability for quantitative analysis; however, the system could be used for quantitative analysis of more advanced particles. Furthermore, our findings demonstrated the applicability of the method for analyzing other clinical samples that require semiquantitative analysis.

\footnotetext{
Abbreviations

PCa: Prostate cancer; RT: Radiation treatment; PSA: Prostate-specific antigen; BCR: Biochemical recurrence; LFIA: Nanoparticle; NC: Nitrocellulose; BSA: Bovine serum albumin; PBS: Phosphate-buffered saline; TEM: Transmission electron microscopy; EDX: Energy dispersive spectroscopy; LOD: Limit of detection; RSD: Relative standard deviation.
}

\section{Supplementary Information}

The online version contains supplementary material available at https://doi. org/10.1186/s12951-021-00817-4.

Additional file 1: Figure S1. Schematic illustration of the preparation of test strip. Figure S2. UV-vis absorption spectra of SiO2@Au-Ag NPs and anti-PSA conjugated SiO2@Au-Ag NPs. Figure S3. Characterization of colloid AuNPs. (a) Transmission electron microscopy (TEM) image. (b) UV-vis extinction spectra. Figure S4. Scanning electron microscope (SEM) images of the test line on the test strip. (a) the test line on the test strip with PSA $0 \mathrm{ng} / \mathrm{mL}$, (b) the test line on the test strip with PSA $300.00 \mathrm{ng} /$ $\mathrm{mL}$. Figure S5. Detection of various concentrations of PSA using colloid AuNPs as a signal reporter in LFIA. (a) Color images and (b) measurement of signal intensity. Error bars represent the standard deviations of the means for three batches of analyte measurements. Figure S6. Application of clinical samples (0.32 ng/mL PSA) with SiO2@Au-Ag NPs as a signal reporter by comparison of test strips detecting $0.3 \mathrm{ng} / \mathrm{mL}$ PSA in LFIA. (a) Color images and (b) measurement of signal intensity. Error bars represent the standard deviations of the means for three batches of analyte measurements.
Acknowledgements

Not applicable.

\section{Authors' contributions}

$\mathrm{HMK}, \mathrm{SL}$, and $\mathrm{BHJ}$ conceived the idea and designed the experiments. HMK, JK, $J A, S B, X H P, K H H, Y C$, and EH performed the experiments. HS, JWK, WYR, DHJ, and $\mathrm{HYL}$ analyzed the data. HMK wrote the manuscript. SL and BHJ supervised the research.

\section{Funding}

This work was supported by the National Research Foundation of Korea (NRF) grant funded by the Korea government (MSIT) (No. NRF2020R1F1A1072702). This study was also supported by the WTU Joint Research Grant of Konkuk University in 2017 (2017-A019-0334).

\section{Availability of data and materials}

All data generated or analyzed during this study are included in this manuscript and its supplementary material.

\section{Declarations}

Ethics approval and consent to participate

Not applicable.

\section{Competing interests}

The authors declare that they have no competing interests.

\section{Consent for publication}

Not applicable.

\begin{abstract}
Author details
${ }^{1}$ Department of Bioscience and Biotechnology, Konkuk University, Seoul, Korea. ${ }^{2}$ Department of Chemistry Education, Seoul National University, Seoul, Korea. ${ }^{3}$ BioSquare Inc, Seongnam, Korea. ${ }^{4}$ School of International Engineering and Science, Jeonbuk National University, Jeonju, Korea. ${ }^{5}$ Department of Nuclear Medicine, Seoul National University Bundang Hospital, Seongnam, Korea. ${ }^{6}$ Department of Urology, Seoul National University Bundang Hospital, Seongnam, Korea.
\end{abstract}

Received: 23 December 2020 Accepted: 26 February 2021 Published online: 12 March 2021

References

1. Rawla P. Epidemiology of prostate cancer. World J Oncol Res. 2019;10:63-89.

2. Ohori M, Wheeler TM, Dunn JK, Stamey TA, Scardino PT. The pathological features and prognosis of prostate cancer detectable with current diagnostic tests. J Urol. 1994;152:1714-20.

3. Schröder FH, Hugosson J, Roobol MJ, Tammela TL, Ciatto S, Nelen V, Kwiatkowski M, Lujan M, Lilja H, Zappa M. Prostate-cancer mortality at 11 years of follow-up. New Engl J Med. 2012;366:981-90.

4. Li X, Li W, Yang Q, Gong X, Guo W, Dong C, Liu J, Xuan L, Chang J. Rapid and quantitative detection of prostate specific antigen with a quantum dot nanobeads-based immunochromatography test strip. ACS Appl Mater Interfaces. 2014;6:6406-14.

5. Andriole GL, Crawford ED, Grubb RL III, Buys SS, Chia D, Church TR, Fouad MN, Gelmann EP, Kvale PA, Reding DJ. Mortality results from a randomized prostate-cancer screening trial. New Engl J Med. 2009;360:1310-9.

6. Aus G, Damber J-E, Khatami A, Lilja H, Stranne J, Hugosson J. Individualized screening interval for prostate cancer based on prostate-specific antigen level: results of a prospective, randomized, population-based study. Arch Intern Med. 2005;165:1857-61.

7. Randazzo M, Beatrice J, Huber A, Grobholz R, Manka L, Chun FK, Recker F, Kwiatkowski M. A "PSA pyramid" for men with initial prostate-specific antigen $\leq 3 \mathrm{ng} / \mathrm{ml}$ : a plea for individualized prostate cancer screening. Eur Urol. 2015;68:591-7.

8. Chung JH, Yu J, Song W, Kang M, Sung HH, Jeon HG, Jeong BC, Seo SI, Lee HM, Jeon SS. Strategy for prostate cancer patients with low prostate specific antigen level (2.5 to 4. ng/mL). J Korean Med Sci. 2020;35:e342-e340. 
9. Heidenreich A, Bastian PJ, Bellmunt J, Bolla M, Joniau S, van der Kwast T, Mason M, Matveev V, Wiegel T, Zattoni F. EAU guidelines on prostate cancer. Part II: treatment of advanced, relapsing, and castration-resistant prostate cancer. Eur Urol. 2014;65:467-79.

10. Peschel RE, Robnett TJ, Hesse D, King CR, Ennis RD, Schiff PB, Wilson LD. PSA based review of adjuvant and salvage radiation therapy vs. observation in postoperative prostate cancer patients. Int J Cancer. 2000;90:29-36.

11. Adhyam M, Gupta AK. A review on the clinical utility of PSA in cancer prostate. Indian J Surg Oncol. 2012:3:120-9.

12. Carroll P, Albertsen P, Greene K, Babaian R, Carter H, Gann P, Han M, Kuban D, Sartor A, Stanford J, Zietman A. PSA Testing for the Pretreatment Staging and Posttreatment Management of Prostate Cancer. Am Urol Assoc 2013.

13. Sathianathen NJ, Konety BR, Alarid-Escudero F, Lawrentschuk N, Bolton DM, Kuntz KM. Cost-effectiveness analysis of active surveillance strategies for men with low-risk prostate cancer. Eur Urol. 2019;75:910-7.

14. Jensen IS, Hathway J, Cyr P, Gauden D, Gardiner P. Cost-consequence analysis of $18 \mathrm{~F}$-fluciclovine for the staging of recurrent prostate cancer. J Mark Access Health Policy. 2020;8:1749362.

15. Roehrborn CG, Black LK. The economic burden of prostate cancer. BJU Int. 2011;108:806-13.

16. Cheng Y-H, Tang H, Yu R-Q, Jiang J-H. DNA-Programmed plasmonic ELISA for the ultrasensitive detection of protein biomarkers. Analyst. 2020;145:4860-6.

17. Li Z, Chen H, Wang P. Lateral flow assay ruler for quantitative and rapid point-of-care testing. Analyst. 2019;144:3314-22.

18. Fu X, Wen J, Li J, Lin H, Liu Y, Zhuang X, Tian C, Chen L. Highly sensitive detection of prostate cancer specific PCA3 mimic DNA using SERS-based competitive lateral flow assay. Nanoscale. 2019;11:15530-6.

19. Yu Q, Li H, Li C, Zhang S, Shen J, Wang Z. Gold nanoparticles-based lateral flow immunoassay with silver staining for simultaneous detection of fumonisin B1 and deoxynivalenol. Food Control. 2015;54:347-52.

20. Manikandan M, Abdelhamid HN, Talib A, Wu H-F. Facile synthesis of gold nanohexagons on graphene templates in Raman spectroscopy for biosensing cancer and cancer stem cells. Biosens Bioelectron. 2014;55:180-6.

21. Abdelhamid HN, Wu H-F. Gold nanoparticles assisted laser desorption/ ionization mass spectrometry and applications: from simple molecules to intact cells. Anal Bioanal Chem. 2016:408:4485-502.

22. Bamrungsap S, Apiwat C, Chantima W, Dharakul T, Wiriyachaiporn N. Rapid and sensitive lateral flow immunoassay for influenza antigen using fluorescently-doped silica nanoparticles. Microchim Acta. 2014;181:223-30.

23. Byzova NA, Zherdev AV, Khlebtsov BN, Burov AM, Khlebtsov NG, Dzantiev BB. Advantages of highly spherical gold nanoparticles as labels for lateral flow immunoassay. Sensors. 2020;20:3608-22.

24. Rodríguez MO, Covián LB, García AC, Blanco-López MC. Silver and gold enhancement methods for lateral flow immunoassays. Talanta. 2016;148:272-8.

25. Gao Z, Ye H, Tang D, Tao J, Habibi S, Minerick A, Tang D, Xia X. Platinumdecorated gold nanoparticles with dual functionalities for ultrasensitive colorimetric in vitro diagnostics. Nano Lett. 2017;17:5572-9.

26. Shen M, Li N, Lu Y, Cheng J, Xu Y. An enhanced centrifugation-assisted lateral flow immunoassay for the point-of-care detection of protein biomarkers. Lab Chip. 2020;20:2626-34.

27. Shen M, Chen Y, Zhu Y, Zhao M, Xu Y. Enhancing the sensitivity of lateral flow immunoassay by centrifugation-assisted flow control. Anal Chem. 2019;91:4814-20.
28. Koczula KM, Gallotta A. Lateral flow assays. Essays Biochem. 2016;60:111-20.

29. Kim H-M, Jeong S, Hahm E, Kim J, Cha MG, Kim K-M, Kang H, Kyeong S, Pham X-H, Lee Y-S. Large scale synthesis of surface-enhanced Raman scattering nanoprobes with high reproducibility and long-term stability. J Ind Eng Chem. 2016;33:22-7.

30. Hwang CSH, Ahn M-S, Lee Y, Chung T, Jeong K-H. Ag/Au alloyed nanoislands for wafer-level plasmonic color filter arrays. Sci Rep. 2019;9:9082-8.

31. Pham X-H, Lee M, Shim S, Jeong S, Kim H-M, Hahm E, Lee SH, Lee Y-S, Jeong DH, Jun B-H. Highly sensitive and reliable SERS probes based on nanogap control of a Au-Ag alloy on silica nanoparticles. RSC Adv. 2017;7:7015-21.

32. Pham X-H, Hahm E, Kang E, Ha YN, Lee SH, Rho W-Y, Lee Y-S, Jeong DH, Jun B-H. Gold-silver bimetallic nanoparticles with a raman labeling chemical assembled on silica nanoparticles as an internal-standardcontaining nanoprobe. J Alloys Compd. 2019;779:360-6.

33. Pham X-H, Hahm E, Huynh K-H, Son BS, Kim H-M, Jeong DH, Jun B-H. 4-Mercaptobenzoic acid labeled gold-silver-alloy-embedded silica nanoparticles as an internal standard containing nanostructures for sensitive quantitative thiram detection. Int J Mol Sci. 2019;20:4841-51.

34. Pham X-H, Hahm E, Kim TH, Kim H-M, Lee SH, Lee Y-S, Jeong DH, Jun B-H. Enzyme-catalyzed Ag growth on Au nanoparticle-assembled structure for highly sensitive colorimetric immunoassay. Sci Rep. 2018;8:6290-6.

35. Pham X-H, Hahm E, Kim TH, Kim H-M, Lee SH, Lee SC, Kang H, Lee H-Y, Jeong DH, Choi HS: Enzyme-amplified SERS immunoassay with Ag-Au bimetallic SERS hot spots. Nano Res. 2020:3338-3346

36. Huynh K-H, Pham X-H, Hahm E, An J, Kim H-M, Jo A, Seong B, Kim $\mathrm{Y}-\mathrm{H}$, Son BS, Kim J. Facile histamine detection by surface-enhanced raman scattering using $\mathrm{SiO}_{2} @$ Au@ Ag alloy nanoparticles. Int J Mol Sci. 2020;21:4048-58.

37. Stöber W, Fink A, Bohn E. Controlled growth of monodisperse silica spheres in the micron size range. J Colloid Interface Sci. 1968;26:62-9.

38. Shim S, Pham X-H, Cha MG, Lee Y-S, Jeong DH, Jun B-H. Size effect of gold on Ag-coated Au nanoparticle-embedded silica nanospheres. RSC Adv. 2016:6:48644-50.

39. Velu R, DeRosa MC. Lateral flow assays for Ochratoxin A using metal nanoparticles: comparison of "adsorption-desorption" approach to linkage inversion assembled nano-aptasensors (LIANA). Analyst. 2018;143:4566-74.

40. Sajid M, Kawde A-N, Daud M. Designs, formats and applications of lateral flow assay: a literature review. J Saudi Chem Soc. 2015;19:689-705.

41. Lynd K, Blum J, Ngoc NTN, Shochet T, Blumenthal PD, Winikoff B. Simplified medical abortion using a semi-quantitative pregnancy test for home-based follow-up. Int J Gynaecol Obstet. 2013;121:144-8.

42. Wang R, Kim K, Choi N, Wang X, Lee J, Jeon JH, Rhie GE, Choo J. Highly sensitive detection of high-risk bacterial pathogens using SERS-based lateral flow assay strips. Sens Actuators B Chem. 2018;270:72-9.

\section{Publisher's Note}

Springer Nature remains neutral with regard to jurisdictional claims in published maps and institutional affiliations.

Ready to submit your research? Choose BMC and benefit from:

- fast, convenient online submission

- thorough peer review by experienced researchers in your field

- rapid publication on acceptance

- support for research data, including large and complex data types

- gold Open Access which fosters wider collaboration and increased citations

- maximum visibility for your research: over $100 \mathrm{M}$ website views per year

At BMC, research is always in progress.

Learn more biomedcentral.com/submissions 